\title{
High efficiency isolated on-board EV battery charger using LLC resonant converter
}

\author{
Sevilay Cetin \\ Technology Faculty, Pamukkale University, Denizli, 20125, Turkey. \\ Corresponding Author: scetin@pau.edu.tr
}

Submitted : 23/05/2020

Revised : :16/04/2021

Accepted :23/05/2021

\begin{abstract}
In this study, high efficiency design of an on-board Electrical Vehicle (EV) battery charger is presented. The presented charger has two stages, where the first stage is conventional front-end boost converter, and the second stage is LLC resonant converter. The basic principles of both stages are discussed, and the detailed design procedures are presented in terms of wide range output voltage regulation, wide range load condition, high efficiency, and high power density. The presented design approach is tested with a prototype implemented with $2.5 \mathrm{~kW}$ output power at $250 \mathrm{~V}-450 \mathrm{~V}$ output voltage range. The peak efficiency of system is obtained as $95.53 \%$ at full load condition.
\end{abstract}

Keywords: On-board battery charger; High efficiency; LLC resonant converter.

\section{INTRODUCTION}

Nowadays, the use of Electrical Vehicle (EV) increases due to depletion of fossil fuels, advantages on global warming, and benefits in the economy. The battery of an EV can be charged from a battery charge station supplying DC voltage or directly any available AC grid with on-board systems. The on-board battery charger gives flexibility to end user by allowing vehicle's battery to be charged from any AC grid at any time and this flexibility increases interest in EVs (Whitaker et al., 2014).

The main problems of on-board system are increased volume, weight, and costs of EV (Yilmazet al., 2013; Grenier et al., 2010; Haghbin et al., 2010; Emadi et al., 2006; Emadi et al.,2008). Therefore, the focus on high power density battery charger design is the state of art in on-board EVs to alleviate costs, improve the performance of the vehicle (Emadi et al., 2006; Emadi et al., 2008). The Lithium-ion (li-ion) battery cells are usually used in EVs due to their high power density especially required at high power ratings (Yilmaz et al., 2013; Chen et al., 2006; Dearborn et al., 2005). The high power density battery charger can be provided with the operation at high switching frequency. However, increasing switching frequency results in low efficiency due to increased switching power losses. Therefore, the new generation SiC device and soft switching converters are usually adapted to the charger (Whitaker et al., 2014). 
A battery charger includes two power conversion stages. The first power conversion stage produces rectified dc voltage from AC grid with power factor correction (PFC) function. The second stage regulates the output of the first power conversion stage according to battery requirements (Whitaker et al., 2014; Yilmaz et al., 2013; (Musavi et al., 2013; Deng et al., 2014). The determination of each power conversion stage is built based on high efficiency at the primary focus and volume at the secondary focus.

A front end AC-DC converter at the first stage usually uses PWM boost DC-DC converter for the PFC function (Musavi et al., 2013; Fang et al., 2015). In order to provide high power density and high efficiency, soft switched dc-dc converters are usually used at the second stage. The resonant converters and phase shifted full bridge pulse width modulated (PSFB-PWM) DC-DC converter are good candidates for the second stage power conversion (Whitaker et al., 2014; Musavi et al., 2013; Deng et al., 2014; Fang et al., 2015; Vu et al., 2018; Wang et al., 2018). The PSFB-PWM converter works with soft switching, but its soft switching feature depends on load condition and dead time optimization (Kim et al., 2013; Kim et al., 2014). Therefore, The PSFB-PWM converter is usually used for constant output voltage applications and designed to work with soft switching under certain load conditions (Badstuebner et al., 2010; Zhao et al., 2009). A battery charger includes constant current (CC) operation mode and constant voltage (CV) operation mode. During CV mode, load decreases and PSFB PWM cannot maintain soft switching operation. Besides, in CC mode, the output voltage changes in a wide range, and dead time optimization is difficult. Thus, resonant converters seem more suitable for wide range load and wide range output voltage regulation required for li-ion battery charge applications due to their load dependent soft switching operation. However, in the resonant converters, changing switching frequency regulates the output voltage. The change of switching frequency limits the design of magnetic components, so it is not desired for high efficiency design optimization. However, the output voltage cannot be regulated at light load conditions when series resonant converter is used. Parallel resonant converter can regulate the output voltage under light load conditions, but circuit components suffer from conduction losses even under light load conditions (Steigerwald, 1988). The LCC resonant converter eliminates disadvantages of series and parallel resonant converters, but ZVS region of this converter takes place at low frequency values and the output filter inductor limits the power density. The LLC resonant converter also eliminates disadvantages of series and parallel resonant topologies. In addition, the wide range output voltage regulation of LLC resonant converter can be provided in a narrow frequency range (Vu et al., 2018; Wang et al., 2018; Steigerwald, 1988; Cetin et al., 2018). Therefore, LLC resonant converter topology is selected in this work due to its benefits for li- ion battery charge applications.

The LLC resonant converter can be adapted to various industrial applications. There are a lot of design procedures of LLC resonant converter in the literature. Most of the proposed design procedures are related fixed output voltage applications (Lu et al., 2006; (Fang et al., 2007; Huang et al., 2011; Biela et al., 2009). The design procedure for battery charger is very different due to the need of wide range output voltage regulation. In Musavi et al., 2013; Deng et al., 2014; Fang et al., 2015; Vu et al., 2018; Wang et al., 2018, design procedure of LLC resonant converter for battery charge applications has been discussed. In Musavi et al., 2013, a design procedure is presented based on lead-acid battery charge which has narrow voltage rates. In Deng et al., 2014, the operation boundary of LLC resonant converter, defining soft switching operation, is presented taken into account li-ion battery charge profile. However, first harmonic approximation (FHA) method is used in the presented design approach. FHA produces accurate results at resonance frequency but produces errors when the switching frequency is far away from resonance frequency especially below resonance frequency (Fang et al., 2015). Another design technique of LLC resonant converter is presented in Fang et al., 2015 taken into consideration time-weight average efficiency in li-ion battery charge characteristic. The time weight average efficiency is determined based on steady state equations. In Vu et al., 2018, a dual full bridge LLC resonant converter is discussed based on CC and CV charge modes of the battery. In Wang et al., 2018, a PWM LLC resonant converter is presented based on wide range output voltage regulation for plug-in EV battery chargers. The design approach applied to the LLC 
resonant converter given in Dow et al., 2011 and Dow et al., 2015 uses FHA which produces errors especially below resonance frequency.

Most of the battery chargers which are using LLC resonant converter, proposed in the literature, discuss the determination of resonant tank components, ZVS region boundary of the LLC resonant converter, improved converter topology, and control methods based on wide range output voltage regulation. A design procedure based on $\mathrm{SiC}$ power semiconductors to provide high efficiency and high power density is presented in Whitaker et al., 2014. This design procedure uses PSFB PWM DC-DC converter at the second stage of the charger and provides high efficiency until certain load condition. However, efficiency of PSFB PWM DC-DC converter reduces at light load conditions due to load dependent soft switching feature of the converter. This work is focused on high efficiency two stage battery charger design using LLC resonant converter. At the second stage, based on wide range load condition and wide range output voltage regulation, required for li-ion battery cells. The SiC power semiconductors are also adapted to the proposed two stage on-board charger. The topology features belonging to each stage are discussed with component determinations, and a power loss analysis is presented to evaluate efficiency target. Finally, the presented design procedure is performed with a prototype with $2.5 \mathrm{~kW}$ peak output power and the output voltage varying between 250 and $450 \mathrm{~V}$. The fundamental operations of each power conversion stage are tested, and the efficiency values are extracted to validate targeted values. The maximum efficiency of full charger is measured around $95.53 \%$ at full load condition. The total volume of the charger is measured as $1.89 \mathrm{~L}$, and the power density is obtained as $1.3 \mathrm{~kW} / \mathrm{kg}$.

\section{DESIGN PROCEDURE}

The circuit schematic of the proposed two stage on-board battery charger is shown in Figure

1. The design procedure that belongs to each power conversion stage is given as below:

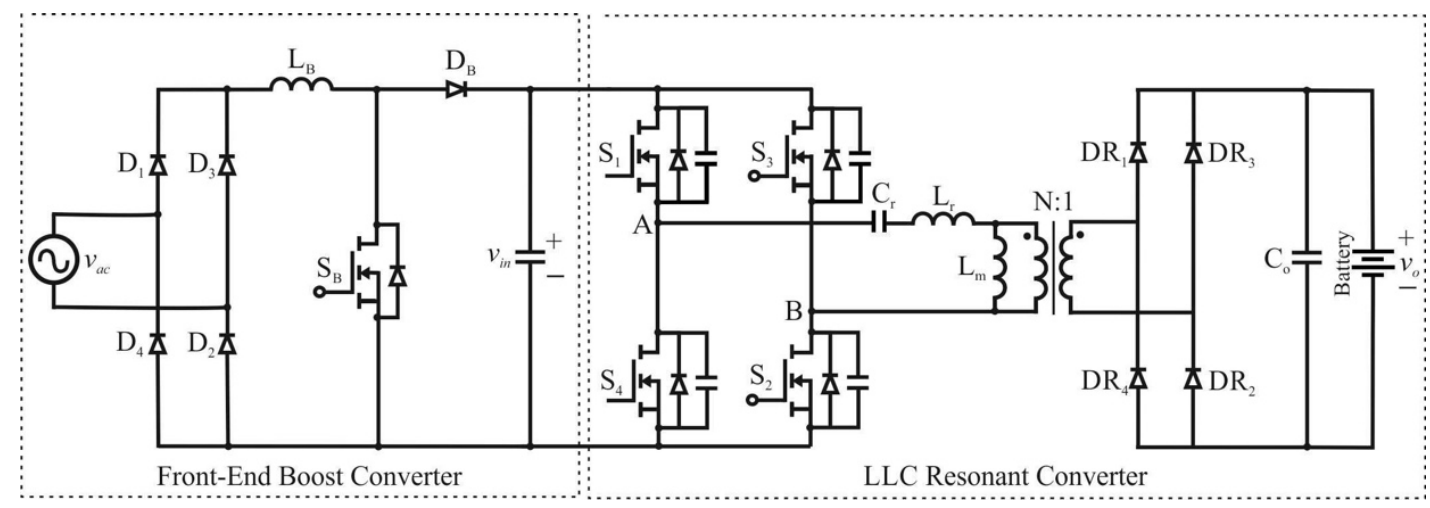

Figure 1. The circuit schematic of proposed two stage on-board battery charger.

\subsection{The First Stage: AC-DC Converter}

The conventional front-end boost converter is used to obtain high power factor, in the proposed battery charger. The new generation SiC power semiconductors are selected to achieve high efficiency and high power density. The SiC schottky diodes have an advantage compared to Si power diodes at high frequency PFC applications due to their almost zero reverse recovery current (Ho et al., 2013). The use of SiC power 
MOSFETs in boost converter extends the operation at high switching frequency further. The high voltage blocking capability of $\mathrm{SiC}$ devices helps to increase efficiency and eliminates the use of snubber components required in conventional design with Si power devices (Mweene et al., 1991). In order to reach high power factor and regulated DC output voltage to be applied to the second stage, commercial preregulators which use average current mode control can be used. The design procedure of power and control stages can be determined according to instructions given in datasheets of commercial preregulators.

\subsection{The Second stage: LLC Resonant DC-DC Converter}

This section discusses the main features and circuit component determinations of LLC resonant DC-DC converter.

\subsubsection{Main Features of LLC Resonant Converter}

The input voltage vin shown in Figure 1 is obtained from the first stage AC-DC converter with PFC function and vo represents the battery charge voltage. S1-S4 are the primary MOSFETs naturally operating with soft switching. DR1-DR4 diodes produce DC output voltage with rectification function. Lm represents the magnetizing inductance of high frequency power transformer, $\mathrm{Cr}$ is the resonant capacitor, and Lr connected in series to the primary side is the resonant inductor. Lr-Lm-Cr represents the resonant tank of the converter.

The two diagonal MOSFET pairs, S1-S2 and S3-S4, share one switching period. They conduct current in a half switching period and produce a square wave voltage across the resonant tank. The voltage gain graphic of the converter with the change of normalized switching frequency $\mathrm{fs} / \mathrm{fr} 1$ is given in Figure 2 . In the extraction of the graphic, FHA method at and above frequency, time domain solution below resonance frequency is used.

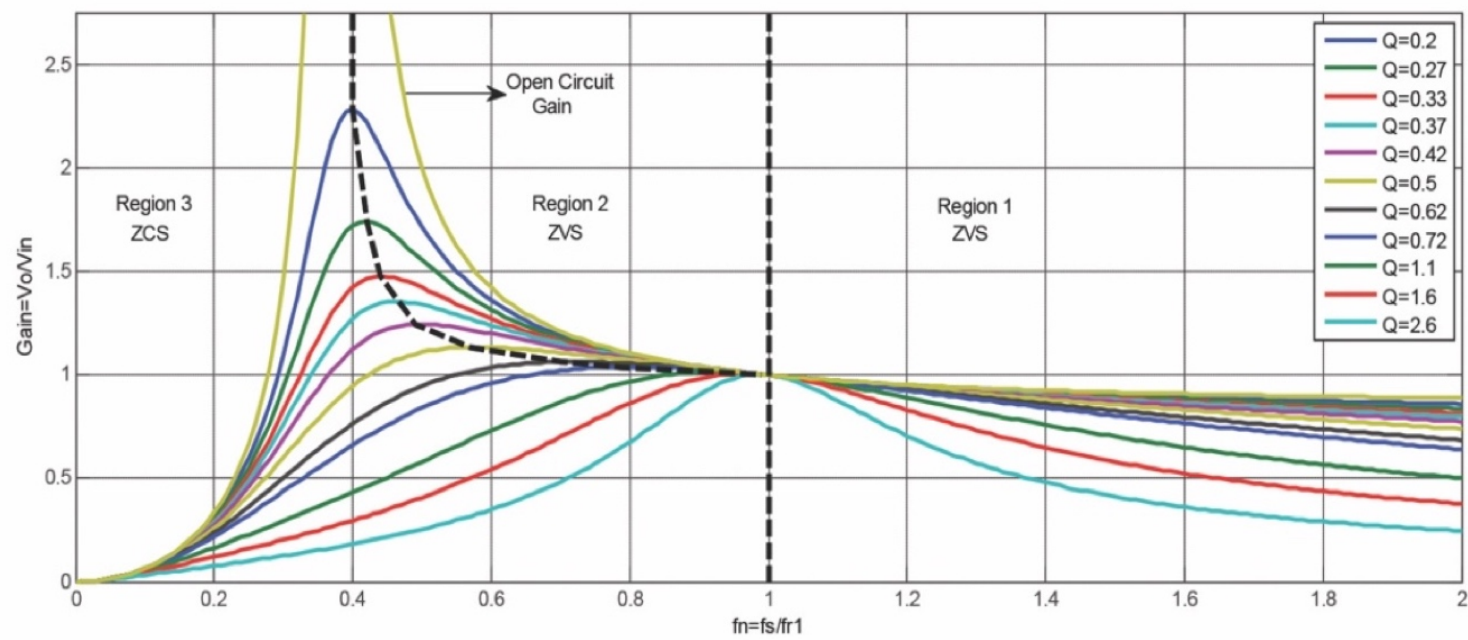

Figure 2. The voltage gain characteristics of LLC DC-DC resonant converter based on FHA.

According to FHA method, the voltage gain of LLC resonant converter is defined as follows (Fang et al., 2007; Simone et al., 2006; Cetin, 2017): 


$$
M=\frac{n V_{o}}{V_{\text {in }}}=\frac{1}{1+\frac{L_{r}}{L_{m}}\left(1-\frac{f_{r 1}{ }^{2}}{f_{s w}{ }^{2}}\right)+j Q\left(\frac{f_{s w}}{f_{r 1}}-\frac{f_{r 1}}{f_{s w}}\right)} .
$$

where fr1 and Q are the first resonance frequency and quality factor, respectively, and they can be given as follows:

$$
\begin{gathered}
f_{r 1}=\frac{1}{2 \pi \sqrt{L_{r} C_{r}}} . \\
Q=\frac{1}{R_{e}} \sqrt{\frac{L_{r}}{C_{r}}} .
\end{gathered}
$$

Re is equivalent ac load resistance reflected to the primary side. Thus, it can be written as follows:

$$
R_{e}=\frac{8}{\pi^{2}} N^{2} R_{L}
$$

The first resonance frequency, $\mathrm{f}_{\mathrm{r} 1}$, occurs by the series resonance between $\mathrm{L}_{\mathrm{r}}$ and $\mathrm{C}_{\mathrm{r}}$. After the removing of the reflected output voltage at the primary side, another resonance occurs including $\mathrm{L}_{\mathrm{r}}, \mathrm{L}_{\mathrm{m}}, \mathrm{C}_{\mathrm{r}}$. Its frequency is defined as second resonance frequency as follows:

$$
f_{r 2}=\frac{1}{2 \pi \sqrt{\left(L_{m}+L_{r}\right) C_{r}}} .
$$

$f_{s w}$ is the switching frequency, and the normalized switching frequency is defined as $f_{n}=f_{s w} / f_{r} 1$.

The voltage gain calculations obtained with FHA method can be acceptable at and above resonance frequency (Simone et al., 2006). However, below resonance frequency, FHA generates errors so it cannot be credible method (Deng et al., 2014; Fang et al., 2015). The steady state solution of the converter to produce correct voltage gain is presented in Lazar et al., 2001; Yu et al., 2012. However, complexity of the nonlinear equations doesn't provide a closed-form solution (Fang et al., 2015). The calculations implemented with computer programming give solution. Therefore, for the below resonance, time domain solution is applied to the converter as given in Shafiei et al., 2017, and closed form gain expression is extracted as given below:

$$
V_{o}=\frac{2 V_{i n}}{(1-\cos \beta) \times n} \times\left[\begin{array}{l}
\frac{\pi}{2 C_{r} R_{L}{ }^{\prime} \omega_{s w}} \\
+\frac{\pi L_{r} \sqrt{L_{m}+L_{r}}}{2 L_{m} \sqrt{L_{r}}} \times \frac{\sin \beta}{\cos \beta-1} \\
-\frac{2 \cos \beta}{\cos \beta-1}+1
\end{array}\right]^{-1} .
$$


Above, RL' represents reflected load resistance and $\beta$ gives radial frequency interval occurring after removing the output voltage reflection across the magnetizing inductance, and it can be written as follows:

$$
\beta=\omega_{r 2} \pi\left(\frac{1}{f_{s w}}-\frac{1}{f_{r 1}}\right) .
$$

$\omega_{\mathrm{r} 2}$ represents the second radial resonance frequency defined as follows:

$$
\omega_{r 2}=2 \pi f_{r 2} .
$$

The characteristic given in Figure 2 shows the behavior of the converter for different operation region and load conditions. In Region 1, buck mode is operated above resonance frequency. In Region 2, converter works below resonance frequency and boost mode is activated. At the first resonant frequency $f_{r 1}, L_{r}$ and $C_{r}$ resonate, and the converter operates as load-independent so the maximum power transfer and the maximum efficiency can be provided. The first resonant frequency is usually selected to optimize the design of the constant voltage applications. However, battery charge applications require wide range output voltage regulation. This work evaluates the optimal operation region according to the desired output voltage regulation and high efficiency. The features of the operation regions shown in Figure 2 can be summarized as below.

In Region 1, above resonance, inductive operation characteristic takes place, and a series resonance occurs between $\mathrm{L}_{\mathrm{r}}$ and $\mathrm{C}_{\mathrm{r}}$. Therefore, primary MOSFETs are turned on with ZVS. However, the commutation of rectifier diodes is hard due to continuous conduction mode (CCM) operation of the converter. Soft commutation of the diodes can be possible with only very light load conditions (Dow et al., 2011; Dow et al., 2015; Fang et al., 2012). The series resonance characteristic cannot regulate the output voltage at light load conditions.

Region 2 shows inductive characteristic, and the converter can be operated in discontinuous conduction mode (DCM). The operation in Region 2 is usually selected when wide output voltage regulation is required since ZVS turn-on of primary switches and zero current switching of rectifier diodes are under guarantee at a very wide range load. However, below resonance operation, Region 3 also takes place and the operation in this region shows capacitive characteristic, providing ZCS turn-off which is not desired for the design implemented with MOSFETs due to their large parasitic capacitance. In order to avoid operation in Region 3, below resonance, a boundary should be clearly defined.

In order to guarantee operation in Region 2, a borderline can be defined separating ZVS and ZCS region by the elimination of sinus expression in the voltage gain expression given with (6). Only resistive components appear at $f_{\mathrm{r} 2}$ and the reactive impedance is zero. As result, the maximum possible dc voltage gain obtained in Region 2, ZVS region, can be written as below:

$$
V_{o-Z V S}=\frac{2 V_{i n}}{(1-\cos \beta) \times n} \times\left[\frac{\pi}{2 C_{r} R_{L}{ }^{\prime} \omega_{s w}}-\frac{2 \cos \beta}{\cos \beta-1}+1\right]^{-1} .
$$

The voltage gain of the converter at no-load condition is extracted with the infinitive value of $R_{L}$ in (6) as below: 


$$
V_{O-N L}=\frac{2 V_{i n}}{(1-\cos \beta) \times n} \times\left[\begin{array}{l}
\frac{\pi L_{r} \sqrt{L_{m}+L_{r}}}{2 L_{m} \sqrt{L_{r}}} \times \frac{\sin \beta}{\cos \beta-1} \\
-\frac{2 \cos \beta}{\cos \beta-1}+1
\end{array}\right]^{-1} .
$$

The second resonance frequency $\mathrm{f}_{\mathrm{r} 2}$ defines the borderline separating ZVS and ZCS region. Therefore, switching frequency range achieving ZVS turn-on in region 2 can be defined between the first resonance frequency and the second resonance frequency as below:

$$
f_{r 2}<f_{s w}<f_{r 1}
$$

\subsubsection{Determination of the Circuit Components}

The turns ratio of the transformer can be determined as follows:

$$
n=\frac{V_{i n}}{V_{o}} .
$$

The resonant inductor, $\mathrm{Lr}$, is determined according to the maximum current limitation and the maximum switching frequency, $\mathrm{f}_{\mathrm{smax}}$, in the short circuit condition as follows:

$$
L_{r-\min }=\frac{V_{\text {in }} n}{8 f_{\text {smax }}} \frac{V_{o-\text { nom }}}{P_{o}} .
$$

where $\mathrm{P}_{0}$ and $\mathrm{V}_{\mathrm{o}-\mathrm{nom}}$ define the output power and the nominal output voltage of the converter. The resonant capacitor, $\mathrm{Cr}$, is selected taking into account the resonant frequency and $\mathrm{Lr}$ as follows:

$$
C_{r}=\frac{1}{\left(2 \pi f_{o}\right)^{2} L_{r-\min }} .
$$

In the determination of the magnetizing inductance $\mathrm{Lm}, \mathrm{ZVS}$ turn-on of primary switches and required output voltage regulation are took into consideration so $\mathrm{Lm}$ has importance in the design of resonant tank parameters.

The ZVS turn-on of MOSFETs can be lost at no-load conditions. Therefore, the energy stored in magnetizing inductance should be enough to charge/discharge parasitic capacitors. Thus, the minimum magnetizing inductance can be defined by

$$
L_{m-\min }=\frac{n V_{o} t_{\text {dead }}}{4 V_{\text {in }}\left(C_{S 1}+C_{S 4}\right) f_{s}} .
$$

Above, tdead is the dead time between the conduction of switches on the same power leg. Cs1 and Cs4 represent the parasitic capacitors of $\mathrm{S} 1$ and $\mathrm{S} 4$. The magnetizing inductance determines the turn-off current of 
MOSFETs and the output voltage regulation. In order to provide the maximum output voltage regulation, the following statement given in Musavi et al., 2013 and Gu et al., 2005 can be used:

$$
L_{m-\max }=\frac{\pi^{2}}{4} L_{r} \frac{\left(1-\frac{f_{s w-\min }}{f_{r 1}}\right)}{\left(\frac{V_{i n}}{n V_{o-\max }}-1\right)} .
$$

Above, fsw-min and Vo-max represent the minimum switching frequency and desired maximum voltage value, respectively.

\section{POWER LOSS ANALYSIS}

The total power loss of two-stage battery charger comes from power MOSFETs, power diodes, and magnetic components including boost inductor of the first stage AC-DC converter and power transformer of the second stage LLC resonant converter. The power loss of each component is defined as follows by the use of datasheet parameter.

\subsection{Power MOSFETs}

The power MOSFETs are used to implement boost switch, SB, of the first stage AC-DC converter and primary switches, S1-S4, of the second stage LLC resonant converter. In order to reach high efficiency and high power density, SiC power MOSFETs are preferred due to its high voltage and high frequency operation capacity. The total loss of SiC MOSFETs includes switching loss, gate drive loss, and conduction loss.

The switching loss of boost MOSFET, $\mathrm{S}_{\mathrm{B}}$, can be written as

$$
P_{S W-S B}=0.5 \times V_{o} \times I_{L B-A V G} \times\left(t_{o n}+t_{o f f}\right) f_{S W} .
$$

Above, $t_{\text {on }}$ and $t_{\text {off }}$ are turn-on and turn-off transition times of $\mathrm{S}_{\mathrm{B}}$, respectively. ILB-AVG is the average current of boost inductor in a half line period. The power loss occurred by the discharge of parasitic capacitor that can be extracted by datasheet parameter.

The primary MOSFETs, S1-S4, of second stage LLC resonant converter turn-on with ZVS and hardly turnoff. The turn-off switching loss can be written as

$$
P_{S W-L L C}=\frac{1}{2} I_{\text {MOSFET-off }} V_{\text {in }} t_{\text {off }} f_{S W} .
$$

Above, IMOSFET-off is the turn-off current of MOSFET. The gate drive loss of MOSFETs at each power stage can be written as

$$
P_{\text {Drive }}=V_{g} \times Q_{g} \times f_{S W}
$$


where $\mathrm{Vg}$ is the gate drive voltage and $\mathrm{Qg}$ is the gate charge of MOSFET. The conduction loss of a MOSFET can be written as follows:

$$
P_{\text {Cond.MOSFET }}=i_{R M S-M O S F E T}^{2} \times R_{D S-o n}
$$

Above, iRMS-MOSFET is the root mean square (RMS) current flowing through MOSFET, and RDS- on is the turn-on resistance of MOSFET.

\subsection{Power Diodes}

Diodes are used to implement diode bridge rectifier composed of D1-D4 and boost diode, DB, of the first stage AC-DC converter. At the second stage LLC resonant converter, diodes, DR1- DR4, are used to produce rectified DC output voltage for the charge of the battery.

All diodes of two-stage battery charger are selected as SiC Schottky diode. It is accepted that diodes have only conduction loss in the charger design since $\mathrm{SiC}$ Schottky diodes have almost zero reverse recovery power loss.

The total conduction loss of diode bridge at the first stage can be defined as follows:

$$
P_{\text {Bridge }}=2 \times I_{L B-A v g} \times V_{F} .
$$

Above, ILB-Avg is the average current of LB inductor in a half of line period and VF is the drop voltage of a diode. The conduction loss of boost diode can be written as

$$
P_{C o n d .-D B}=I_{D B-A V G} \times V_{F}
$$

were IDB-AVG and $\mathrm{V}_{\mathrm{F}-\mathrm{DB}}$ are the average currents of boost diode. The total conduction loss of rectifier diodes at the second stage LLC resonant converter can be given as

$$
P_{\text {cond }-\mathrm{rec}-L L C}=\frac{I_{o}}{2} V_{F}
$$

\subsection{Magnetic Components: Boost Inductor, Resonant Inductor and Power Transformer}

Magnetic components have copper and core loss. The conduction loss occurred in the boost inductor and resonant inductor can be defined as follows:

$$
\begin{aligned}
& P_{\text {cond. }-L B}=I_{L B-R M S}{ }^{2} \times R_{L B} \\
& P_{\text {cond.-Lr }}=I_{L r-R M S}{ }^{2} \times R_{L r}
\end{aligned}
$$


Above, ILB-RMS and ILB-RMS are the RMS current value of boost inductor and resonant inductor. RLB and RLr are the resistance of the boost inductor and resonant inductor, respectively.

The conduction loss of the transformer can be written as

$$
P_{\text {cond-TR }}=I_{R M S-p r}^{2} R_{p r-a c}+2 I_{R M S-s e c}{ }^{2} R_{\text {sec }-a c}
$$

IRMS-pr and IRMS-sec are the RMS value of the currents flowing through primary and secondary windings of the transformer. Rpr-ac and Rsec-ac are the ac resistance of the primary and secondary windings of the transformer. The core losses of boost inductor, resonant inductor, and the power transformer can be extracted with datasheet parameters of the core material.

\section{DESIGN CASE}

In this section, the proposed design procedure is applied to two-power stage battery charger as an analysis to determine the conditions and operations providing the maximum efficiency. The initial design specifications are given in Table 1. In the design case, the output voltage regulation range is accepted as $250 \mathrm{~V}-450 \mathrm{~V}$. The input of the charger can be fed by any AC power source changing between 85 and 265 VRMS. The analog control design is applied to each power stage of the charger. UCC3818 preregulator which uses average current mode control is selected for the first stage AC-DC converter with PFC function. The values of the other circuit components are determined according to design procedure given earlier and summarized in Table 2.

Table 1. Two-stage charger initial design specifications.

\begin{tabular}{|l|c|}
\hline \multicolumn{1}{|c|}{ Parameter } & Value \\
\hline AC input voltage (single phase) & $85-265 \mathrm{VRMS}$ \\
\hline Nominal input frequency & $50 \mathrm{~Hz}$ \\
\hline DC bus voltage & $380 \mathrm{~V}$ \\
\hline DC bus voltage ripple & $\% 15$ \\
\hline AC-DC converter frequency & $100 \mathrm{kHz}$ \\
\hline AC-DC converter peak efficiency & $98 \%$ \\
\hline The output voltage & $250-450 \mathrm{~V}$ \\
\hline DC-DC converter frequency & $110-200 \mathrm{kHz}$ \\
\hline DC-DC converter efficiency & $96 \%$ \\
\hline Full system peak efficiency & $>94 \%$ \\
\hline Input current THDi at full power & $<5 \%$ \\
\hline Power factor at full power & $>0.99$ \\
\hline Full system mass & $<2 \mathrm{~kg}$ \\
\hline Full system volume & $<1.9 \mathrm{~L}$ \\
\hline Full system power & $2.5 \mathrm{~kW}$ \\
\hline
\end{tabular}


Table 2. The used components in two stage battery charger.

\begin{tabular}{|c|c|c|}
\hline \multicolumn{3}{|c|}{$\mathrm{P}_{\mathrm{O}}=2.5 \mathrm{~kW}, \mathrm{~V}_{\mathrm{O}}=250-450 \mathrm{~V}$, and $\mathrm{Vac}=85 \mathrm{VRMS}-265 \mathrm{VRMS}$} \\
\hline \multirow{5}{*}{$\begin{array}{c}\text { First } \\
\text { stage } \\
\text { AC-DC } \\
\text { converter }\end{array}$} & $\mathrm{SB}$ & $\begin{array}{l}\mathrm{SiC} \text { C2M0040120D-ND } \\
1200 \mathrm{~V} 60 \mathrm{~A}, \mathrm{RDS}=40 \mathrm{~m} \Omega\end{array}$ \\
\hline & DB & $\begin{array}{l}\text { SiC C4D20120H } \\
20 \mathrm{~A} 1200 \mathrm{~V}\end{array}$ \\
\hline & D1-D4 & $\begin{array}{l}\text { C4D40120D-ND } \\
1200 \mathrm{~V}, 27 \mathrm{~A}\end{array}$ \\
\hline & $\mathrm{Co}_{\mathrm{O}}$ & $470 \mu \mathrm{F}$ electrolytic, $47 \mathrm{nF}$ ceramic \\
\hline & LB & $\begin{array}{l}72 \mu \mathrm{H}, \mathrm{NLB}=31 \text { (homemade) } \\
\text { toroid Kool } \mathrm{Mu} 0077777 \mathrm{~A} 7, \mathrm{Bmax}=0.22 \mathrm{~T}\end{array}$ \\
\hline \multirow{8}{*}{$\begin{array}{l}\text { Second } \\
\text { stage LLC } \\
\text { resonant } \\
\text { DC-DC } \\
\text { converter }\end{array}$} & $\mathrm{Lr}$ & $\begin{array}{l}26 \mu \mathrm{H}, \mathrm{NLr}=12, \mathrm{E} 42 / 21 / 15 \text { (homemade) } \\
\mathrm{Bmax}_{\max }=0.15 \mathrm{~T}-0.12 \mathrm{~T}, \mathrm{lg}=1.2 \mathrm{~mm}\end{array}$ \\
\hline & $\mathrm{Lm}$ & $130 \mu \mathrm{H}$ \\
\hline & $\mathrm{Cr}$ & $\begin{array}{l}24 \mathrm{nF}, 1 \times 0.47 \mathrm{nF}, \text { PHE450TD4470JR06L2 } \\
\text { 2x2x10 nF, PHE450TB5100JB16R17 }\end{array}$ \\
\hline & RL & $81 \Omega-810 \Omega$ \\
\hline & $\mathrm{S} 1-\mathrm{S} 4$ & $\begin{array}{l}\mathrm{SiC} \text { C2M0040120D } \\
1200 \mathrm{~V}, 60 \mathrm{~A}, \mathrm{RDS}=40 \mathrm{~m} \Omega\end{array}$ \\
\hline & DR1-DR4 & SiC C4D30120D, $1200 \mathrm{~V}, 43 \mathrm{~A}$ \\
\hline & $\mathrm{Co}_{\mathrm{O}}$ & $\begin{array}{l}4 \mu \mathrm{F} \text { ceramic } \\
4 \mathrm{x} \text { CKG57NX7T2J105M500JH }\end{array}$ \\
\hline & TR & $\begin{array}{l}\mathrm{NP}=10, \mathrm{NS}=6, \mathrm{E} 65 / 32 / 27 \text { (homemade) } \\
\Delta \mathrm{B}=0.14 \mathrm{~T}-0.07 \mathrm{~T} \text {, and } \mathrm{lg}=0.5 \mathrm{~mm}\end{array}$ \\
\hline
\end{tabular}

In order to determine performance of design case, an analytical efficiency analysis is applied separately to each power conversion stage according to the determined circuit components and operation points. 
The analytical efficiency analysis of the first stage AC-DC converter is given in Figure 3. In the graphics, the line voltage between 85 and 265 VRMS is applied to the converter and the efficiency is obtained as function of load condition. The power loss distribution is also given in Figure 4, at 220 VRMS AC line voltage and full load condition. The maximum efficiency is calculated as $98.51 \%$ at 265 VRMS. The efficiency values at $110 V_{\text {RMS }}$ are lower compared to $220 \mathrm{~V}_{\mathrm{RMS}}$ and $265 \mathrm{~V}_{\mathrm{RMS}}$ due to increasing conduction loss for same output power level. The efficiency values of the converter decrease with the increase of load, since the conduction loss is dominated into total power loss. The analytical peak efficiency value provides targeted efficiency for the first stage AC-DC converter.

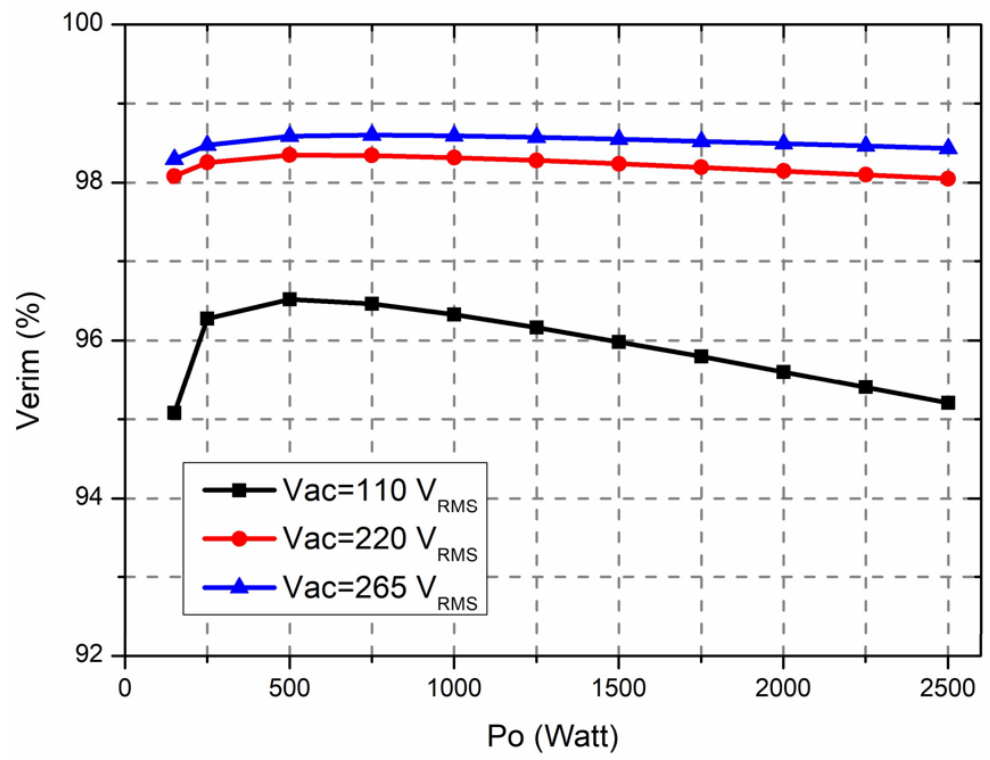

Figure 3. The analytical efficiency variation of the first stage AC-DC converter as function of load condition.

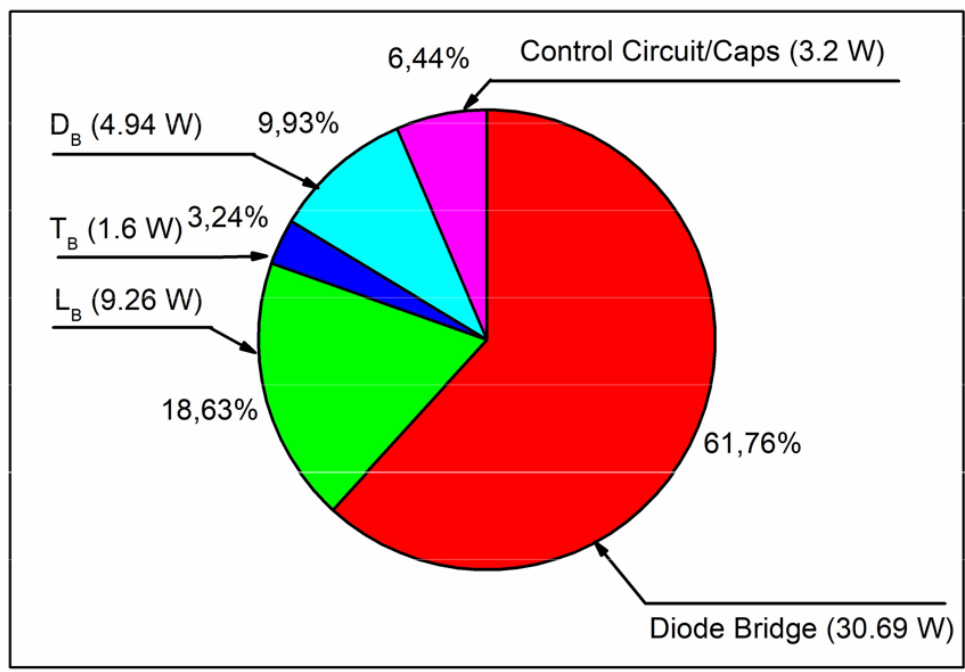

Figure 4. The loss breakdown of first stage AC-DC converter at 220 VRMS and full load. 
At the second stage, operation of LLC resonant converter is firstly evaluated based on targeted output voltage regulation. The evaluation results are summarized in Table 3. For the below resonance operation (BRO), the turns ratio of the transformer is set at fr1. At fr1, targeted minimum output voltage, $250 \mathrm{~V}$, can be provided at the maximum value of the input voltage. The switching frequency is decreased to increase the battery voltage. The switching frequency should be higher than the second resonance frequency to avoid operation in Region 3.

Table 3. The output voltage regulation of LLC resonant converter at different operation conditions.

\begin{tabular}{|c|c|c|c|c|c|}
\hline $\begin{array}{l}\text { Operation } \\
\text { condition }\end{array}$ & Turns ratio, $\mathrm{N}$ & \multicolumn{2}{|c|}{$\begin{array}{c}\text { Switching frequency range } \\
\text { Vin-min }=350 \mathrm{~V} \quad \text { Vin-max }=410 \mathrm{~V}\end{array}$} & Load condition & $\begin{array}{l}\text { Output } \\
\text { voltage } \\
\text { range }\end{array}$ \\
\hline $\mathrm{BRO}$ & $N=\frac{\overline{V_{i n-\max }}}{V_{o-\min }}=\frac{4 \overline{10}}{250}=1.64$ & $\begin{array}{c}106-150 \mathrm{kHz} \\
114.5-158 \mathrm{kHz}\end{array}$ & $\begin{array}{c}115-196 \mathrm{kHz} \\
121.5-196 \mathrm{kHz}\end{array}$ & $\begin{array}{c}\text { Full Load (5A) } \\
10 \% \operatorname{Load}(0.5 \mathrm{~A})\end{array}$ & $\begin{array}{l}450-250 \mathrm{~V} \\
450-250 \mathrm{~V}\end{array}$ \\
\hline ABRO & $N=\frac{V_{i n-\min }}{V_{o-\min }}=\frac{350}{250}=1.4$ & $\begin{array}{l}111.5-200 \mathrm{kHz} \\
119.5-202 \mathrm{kHz}\end{array}$ & $\begin{array}{l}125-359 \mathrm{kHz} \\
130-400 \mathrm{kHz}\end{array}$ & $\begin{array}{c}\text { Full Load (5A) } \\
10 \% \operatorname{Load}(0.5 \mathrm{~A})\end{array}$ & $\begin{array}{l}450-250 \mathrm{~V} \\
450-250 \mathrm{~V}\end{array}$ \\
\hline ARO & $N=\frac{V_{\text {in-min }}}{V_{- \text {o-max }}}=\frac{350}{4 \underline{50}}=0.78$ & $\begin{array}{l}\text { 201-458 kHz } \\
\text { 201-No Reg. }\end{array}$ & $\begin{array}{c}268-547 \mathrm{kHz} \\
532 \mathrm{kHz}-\text { No Reg. }\end{array}$ & $\begin{array}{c}\text { Full Load }(5 \mathrm{~A}) \\
10 \% \text { Load }(0.5 \mathrm{~A})\end{array}$ & $\begin{array}{c}\text { 450-250V } \\
\text { 450-No Reg. }\end{array}$ \\
\hline
\end{tabular}

Note: In the calculations, $\mathrm{f}_{\mathrm{r}}=201 \mathrm{kHz}, \mathrm{f}_{\mathrm{r} 2}=82.25 \mathrm{kHz}, \mathrm{L}_{\mathrm{r}}=26 \mu \mathrm{H}, \mathrm{Cr}_{\mathrm{r}}=24 \mu \mathrm{F}$, and $\mathrm{Lm}_{\mathrm{m}}=130 \mu \mathrm{H}$.

For both above and below resonance operations (ABRO), transformer turns ratio is set at $f_{\mathrm{r} 1}$ to regulate the minimum output voltage when the input voltage has its minimum. The switching frequency is increased to obtain low values of the battery voltage.

For the above resonance operation (ARO), the turns ratio of the transformer is determined at $\mathrm{f}_{\mathrm{r} 1}$ to provide the maximum output voltage regulation at the minimum value of the input voltage. In this operation mode, the switching frequency has to be increased to obtain lower values of the battery voltage. However, the minimum output voltage regulation cannot be provided at no-load condition at ARO.

The converter can work with $\mathrm{BRO}$ and $\mathrm{ABRO}$ based on the obtained results given in Table 3. However, BRO in Region 2 is good candidate to reach high efficiency compared to ABRO, since the rectifier diodes cannot softly commutate when the switching frequency is above resonance. Besides, BRO provides targeted output voltage regulation with a narrow switching frequency range.

The efficiency of the second stage LLC resonant converter is extracted for BRO as function of load condition and given in Figure 5 at $450 \mathrm{~V}$ output voltage. The loss breakdown is also given in Figure 6 at $450 \mathrm{~V}$ output voltage and full load. According to the obtained analytical results, the maximum efficiency is around $97.91 \%$. 
Thus, analytical efficiency values provide targeted efficiency for the second stage LLC resonant DC-DC converter.

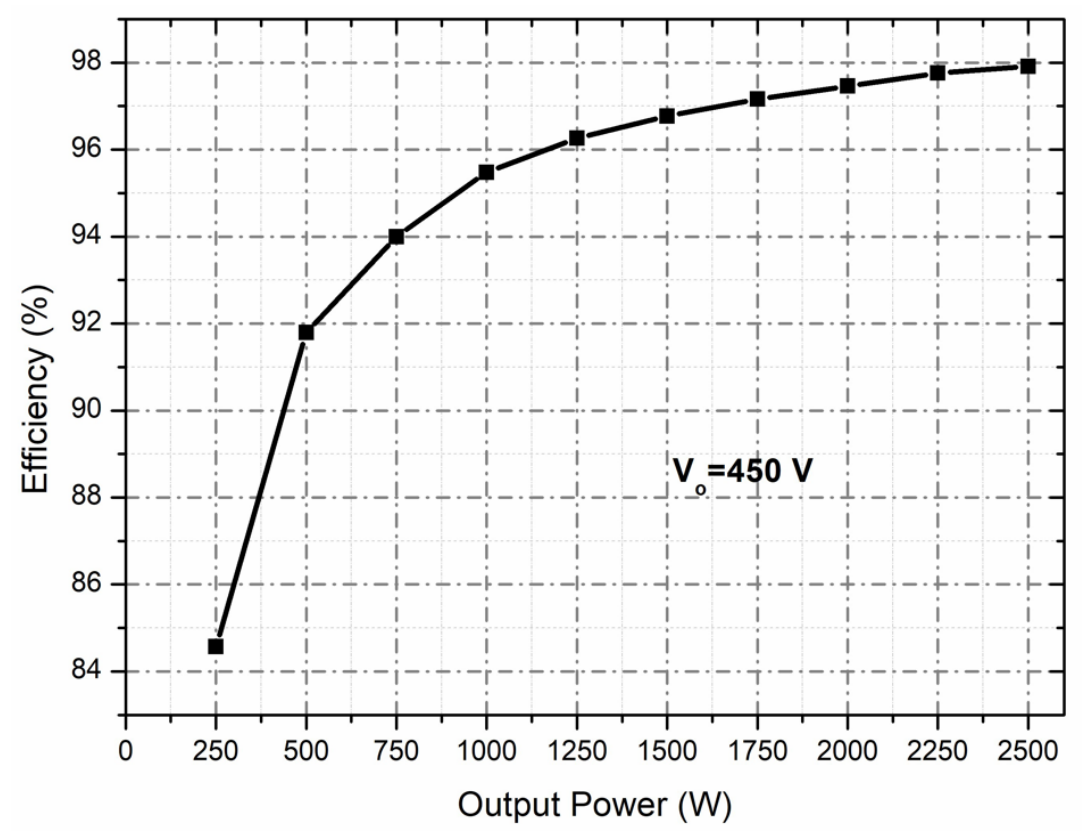

Figure 5. The analytical efficiency variation of second stage LLC resonant DC-DC converter as function of load condition at $\mathrm{vo}=450 \mathrm{~V}$.

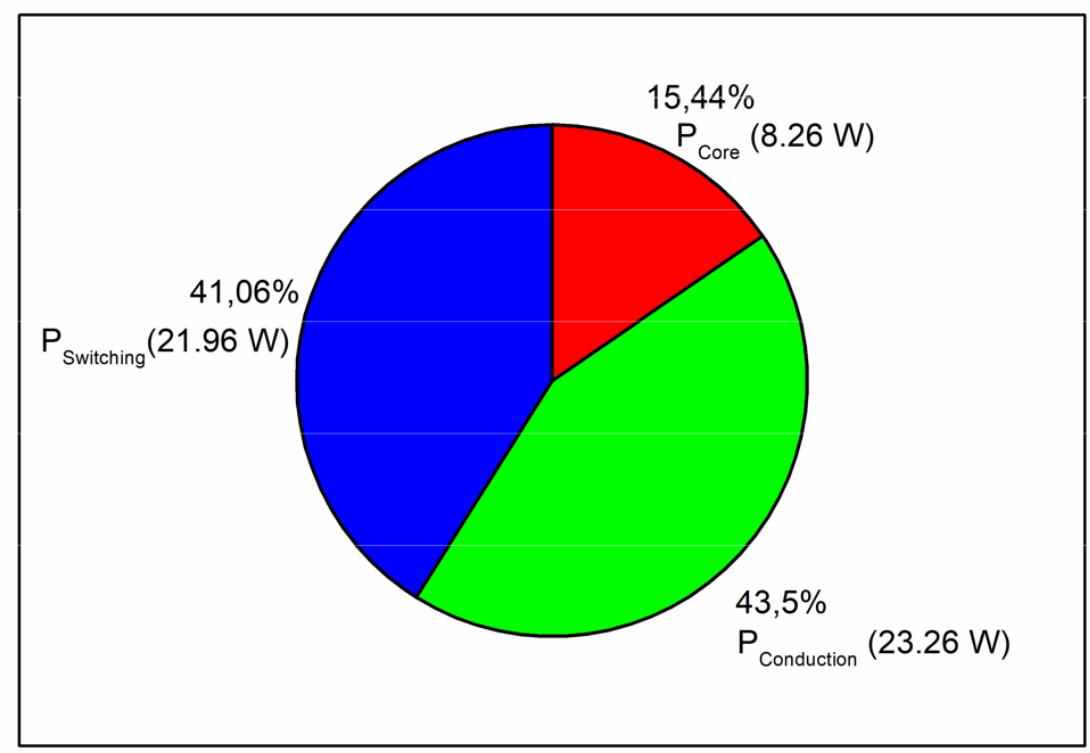

Figure 6. The loss breakdown of the second stage DC-DC converter at $450 \mathrm{~V}$ output voltage and full load 


\section{EXPERIMENTAL RESULTS}

A prototype is built in laboratory to test presented design procedure for on-board battery charger. The first stage AC-DC converter and the second stage LLC resonant converter are separately tested. In the prototype, determined components given in Table 2 are used. The first stage is tested for universal line voltage changing between 85 and $265 \mathrm{~V}_{\mathrm{RMS}}$, at $100 \mathrm{kHz}$. The obtained line voltage and the current waveforms are given in Figure 7, while the input voltage is $110 \mathrm{VRMS}$ and $265 \mathrm{~V}_{\mathrm{RMS}}$, at full load condition. The power factor (PF) is measured as 0.9989 and 0.9974 at $110 \mathrm{~V}_{\mathrm{RMS}}$ and $265 \mathrm{~V}_{\mathrm{RMS}}$, respectively. A little phase displacement between line current and voltage comes from second harmonic of the line frequency on the reference current generating by UCC3818 controller, but PF is still close to unity and within limits.

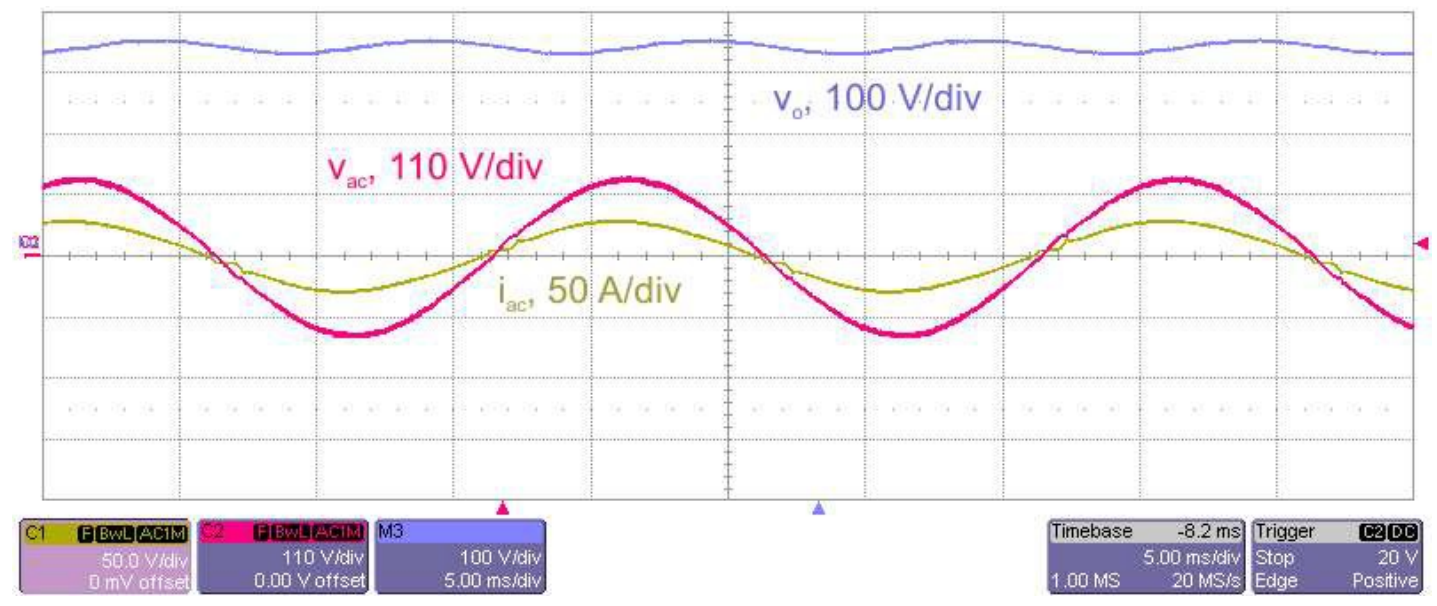

(a)110 VRMS

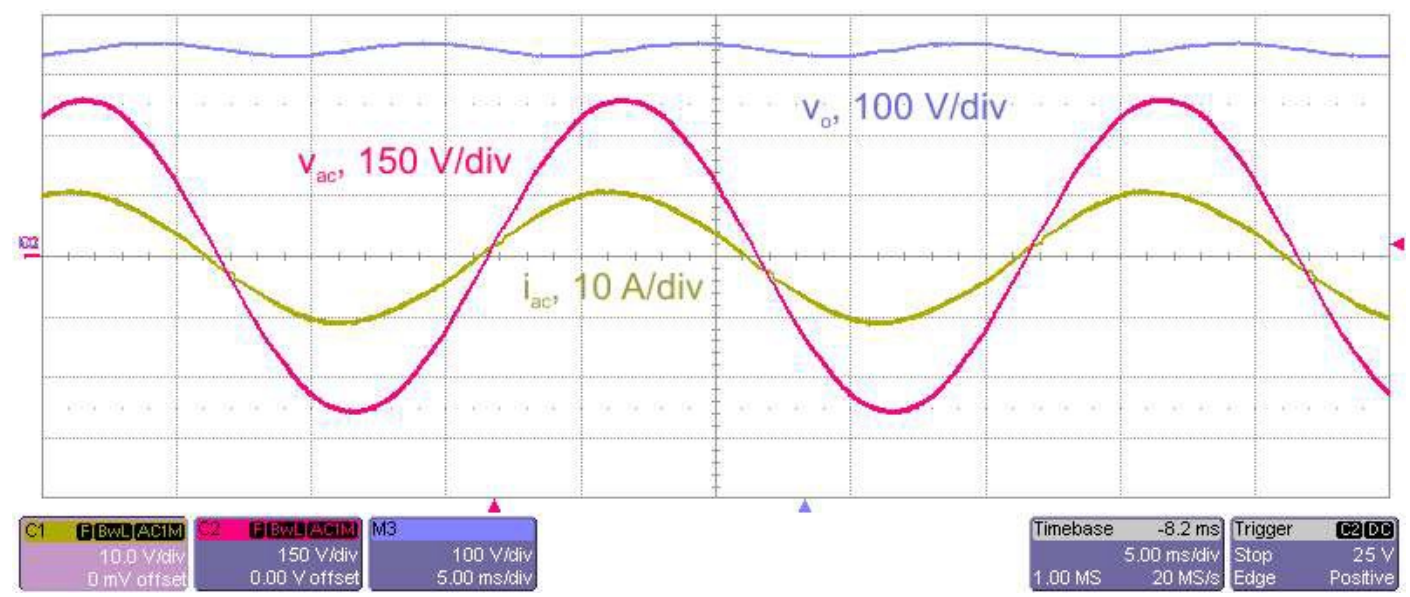

(b) 265 VRMS

Figure 7. The input current and voltage waveforms of the first stage AC-DC converter with $380 \mathrm{~V}$ output voltage at full load condition. The input voltage is (a) 110 VRMS and (b) 265 VRMS. 
The efficiency values as function of load variation, at different line voltages, are compared in Figure 8 . The efficiency values decrease, while the input voltage vac is decreasing due to increased conduction losses. The maximum efficiency is measured as $98.22 \%$ at 265 VRMS.

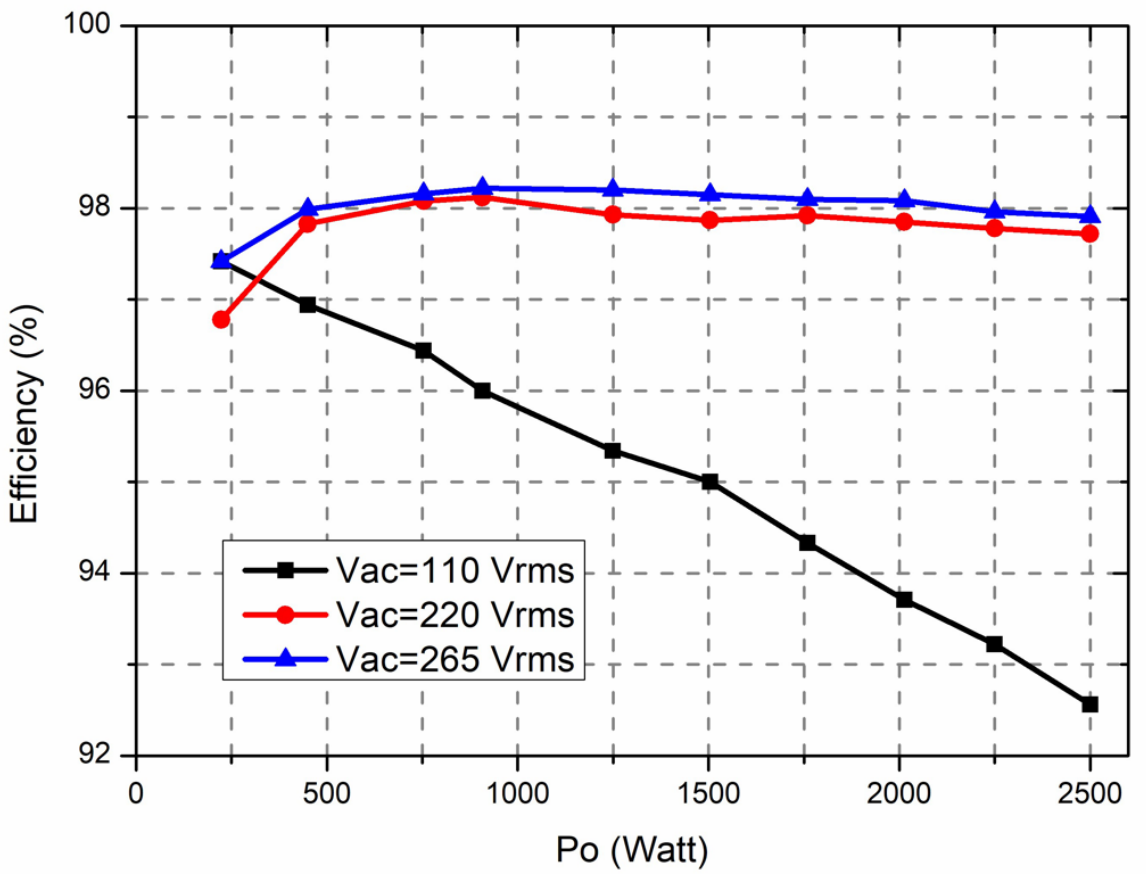

Figure 8. Efficiency comparison as function of load variation at different line voltages.

The operation of the second stage LLC resonant converter is tested for the output voltage range changing between $250 \mathrm{~V}$ and $450 \mathrm{~V}$. A DC power source is used for the input voltage and an electronic load is used to simulate battery charge profile. The frequency modulation control was used to test the performance of theconverter. An abgand open loopcontrolcircuitwere designed by the use of logic gates and delay circuits to adjust the required operation frequency regulating the output voltage.

The desired maximum output voltage is tested for the worst case, at full load condition. According to the measurement results, the maximum output voltage, $450 \mathrm{~V}$, is obtained around $120 \mathrm{kHz}$, below resonance. The measured waveforms are given in Figure 9. The minimum output voltage regulation is tested at worst case condition, at light load condition. The targeted minimum output voltage, $250 \mathrm{~V}$, is obtained around $192.5 \mathrm{kHz}$ at $10 \%$ load condition. The measured waveforms are given in Figure 10. The measured waveforms validate the output voltage regulation and ZVS turn-on of primary MOSFET $\mathrm{S}_{1}$ and fundamentals of LLC resonant converter. The output current and voltage waveforms are given in Figure 11 and Figure 12 when the output voltage is $250 \mathrm{~V}$ and $450 \mathrm{~V}$, respectively. The maximum output current ripple is measured as $0.2 \mathrm{~A}$.

The efficiency of the second stage is also extracted as function of load condition while the output voltage is $250 \mathrm{~V}$. The obtained values are given in Figure 13. The peak efficiency of the second stage is measured as $97.2 \%$ around $1.7 \mathrm{~kW}$ output power. The operation of the second stage is tested until $1.7 \mathrm{~kW}$ output power, due to the current capacity limitation of the used DC power source. The operation test for further power levels is performed with two-stage charger. 


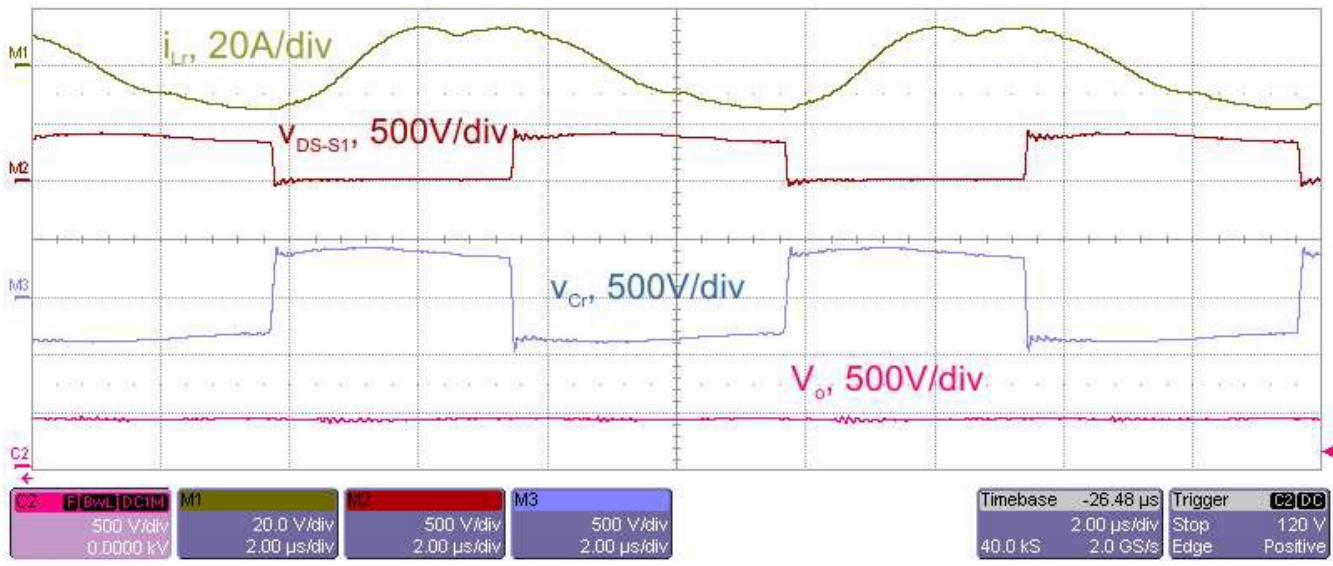

Figure 9. The waveforms of LLC resonant converter: $\mathrm{Vin}=380 \mathrm{~V}, \mathrm{~V}_{\mathrm{o}}=450 \mathrm{~V}, \mathrm{Io}_{\mathrm{o}}=4 \mathrm{~A}$, and $\mathrm{s}=125.52 \mathrm{kHz}$.

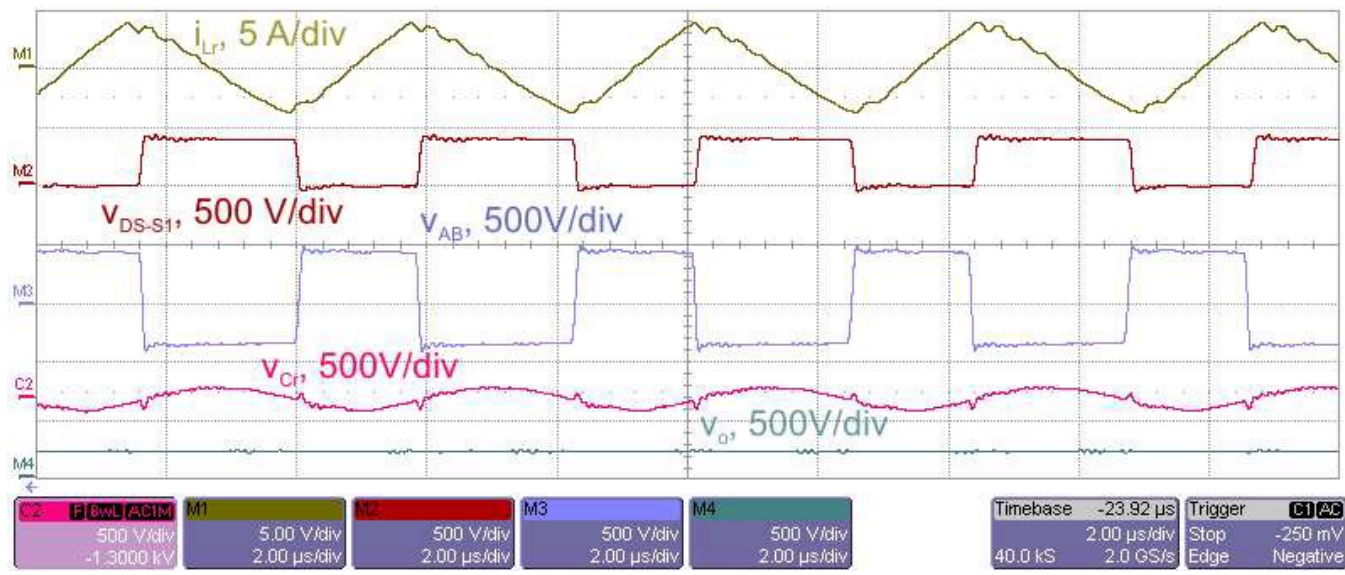

Figure 10. The waveforms of LLC resonant converter: $\mathrm{Vin}_{\mathrm{in}}=380 \mathrm{~V}, \mathrm{~V}_{\mathrm{o}}=250 \mathrm{~V}, \mathrm{I}_{\mathrm{o}}=0.63 \mathrm{~A}$, and fs $=192.5 \mathrm{kHz}$.

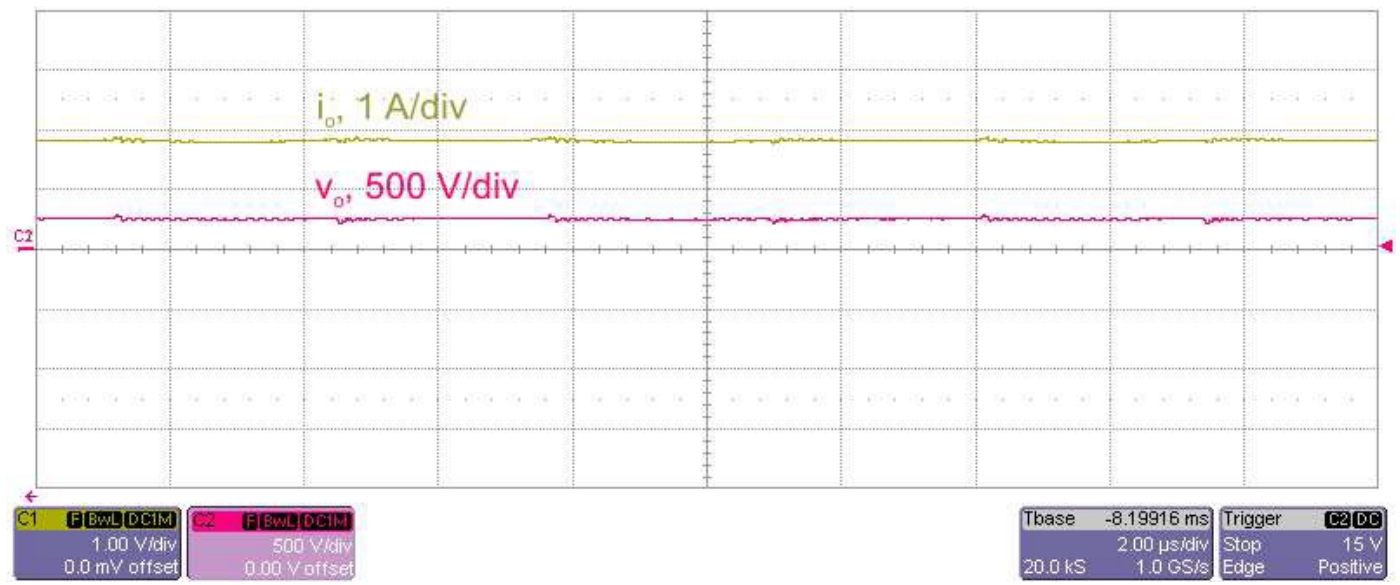

Figure 11. The output voltage and output current waveforms: $\mathrm{V}_{\mathrm{o}}=250 \mathrm{~V}, \mathrm{I}_{\mathrm{o}}=1.8 \mathrm{~A}$. 


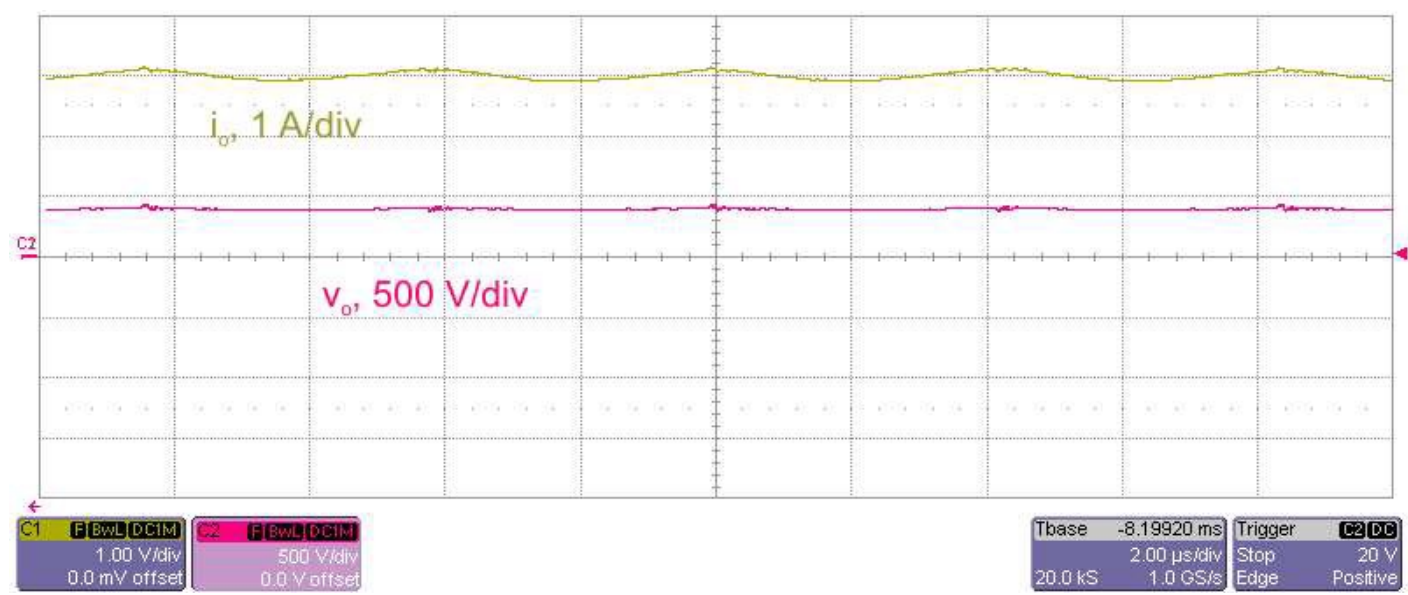

Figure 12. The output voltage and output current waveforms: $\mathrm{V}_{\mathrm{o}}=450 \mathrm{~V}, \mathrm{I}_{\mathrm{o}}=3 \mathrm{~A}$.

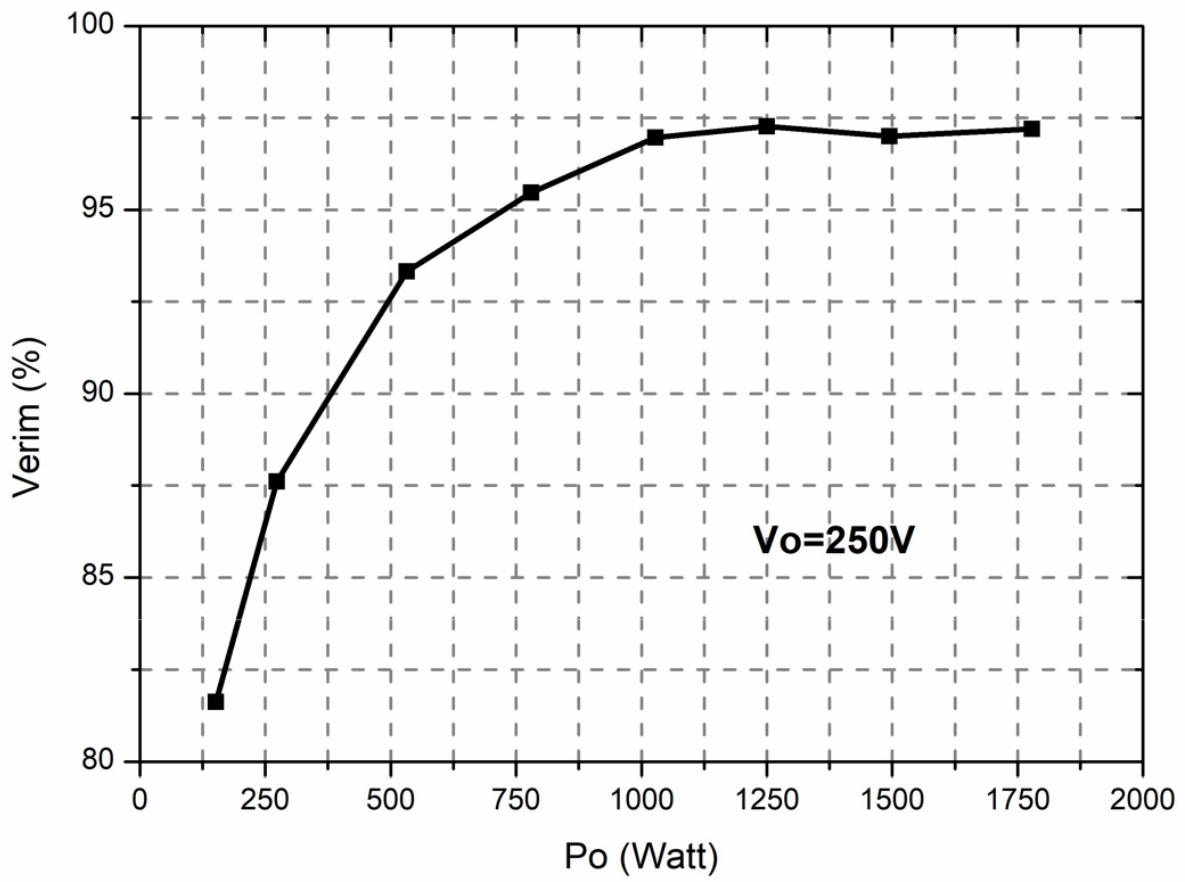

Figure 13. Efficiency values of LLC resonant converter as function of load condition while $\mathrm{V}_{\mathrm{o}}=250 \mathrm{~V}$.

In the test of full charger, the first stage AC-DC converter is connected to the input of the second stage LLC resonant converter and an electronic resistive load is used to simulate battery charge characteristic. The input current, voltage, and the output voltage waveforms are measured and given in Figure 14 for $450 \mathrm{~V}$ output voltage and 2.3 $\mathrm{kW}$ output power. In Figure 15, measured input current, voltage, and the output voltage waveforms are given for $250 \mathrm{~V}$ output voltage and $1.25 \mathrm{~kW}$ output power. 
The measured efficiency values and their comparison with analytical results of two-stage charger are given in Figure 16 at different load conditions and $450 \mathrm{~V}$ output voltage. The comparison results appear to be consistent with each other and the peak efficiency is measured as $95.53 \%$. The power factor (PF) and total harmonic distortion of the input current (THDi) are measured for two-stage charger at full load condition, and the obtained measurement results based on output voltage variation are given in Figure 17. The PF is always above 0.996, and THDi is within limits during the output voltage change.

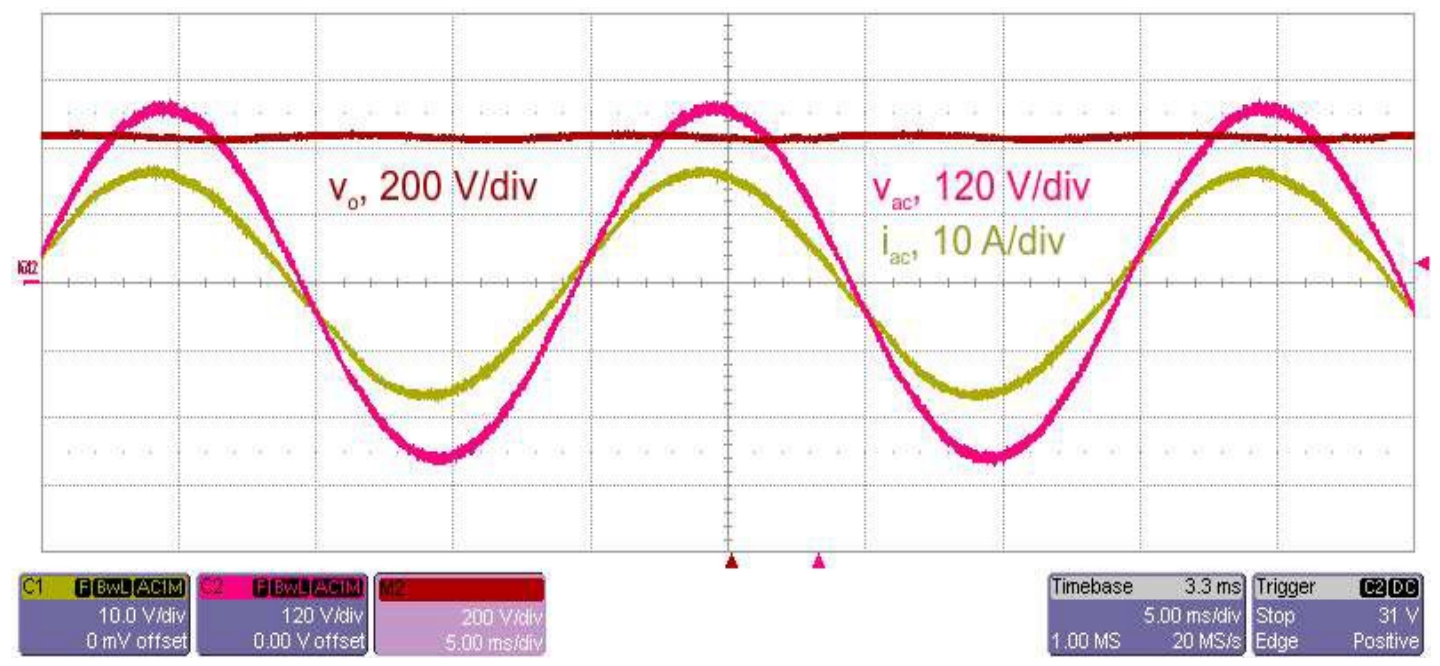

Figure 14. The input and output waveforms of two-stage charger with $\mathrm{vac}=220 \mathrm{~V}, \mathrm{~V}_{\mathrm{o}}=450 \mathrm{~V}, \mathrm{I}_{\mathrm{o}}=5 \mathrm{~A}$, and $90 \Omega$ resistive load.

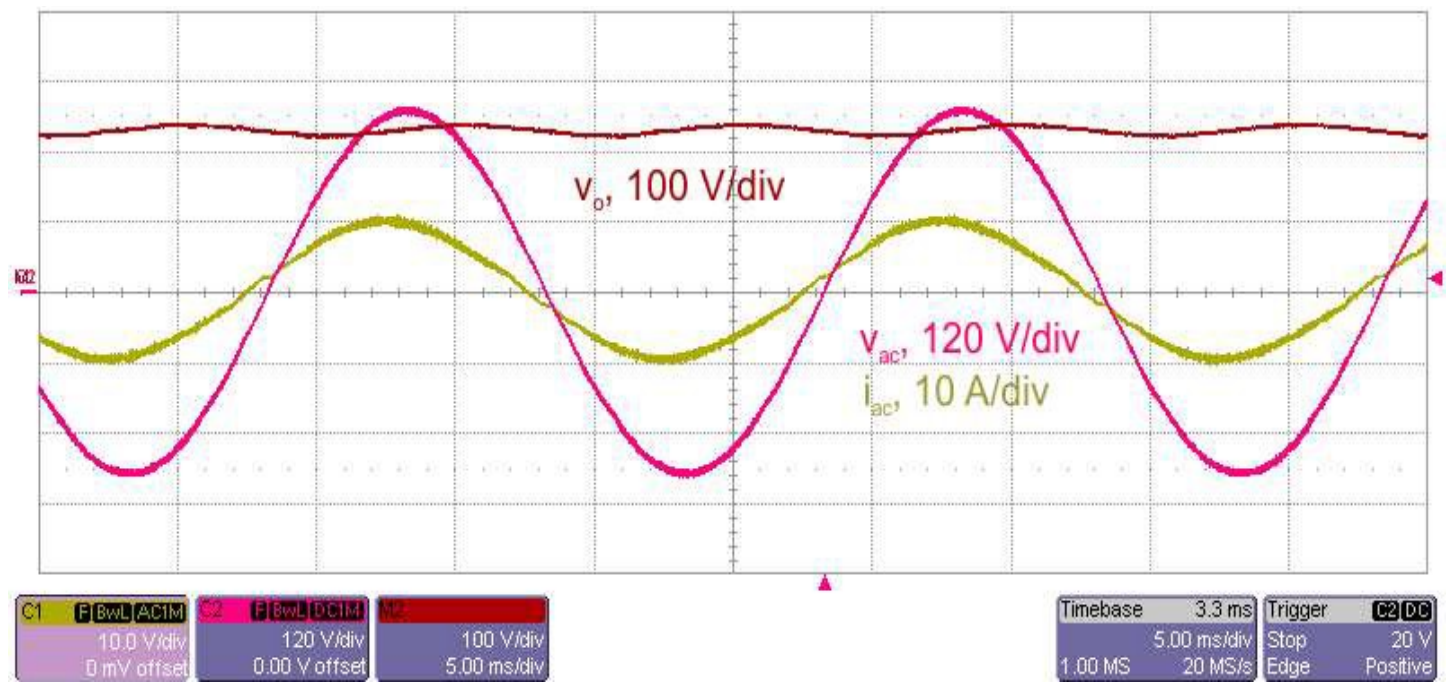

Figure 15. The input and output waveforms of two-stage charger with vac $=220 \mathrm{~V}, \mathrm{~V}_{\mathrm{o}}=250 \mathrm{~V}, \mathrm{I}_{\mathrm{o}}=5 \mathrm{~A}$, and $50 \Omega$ resistive load. 


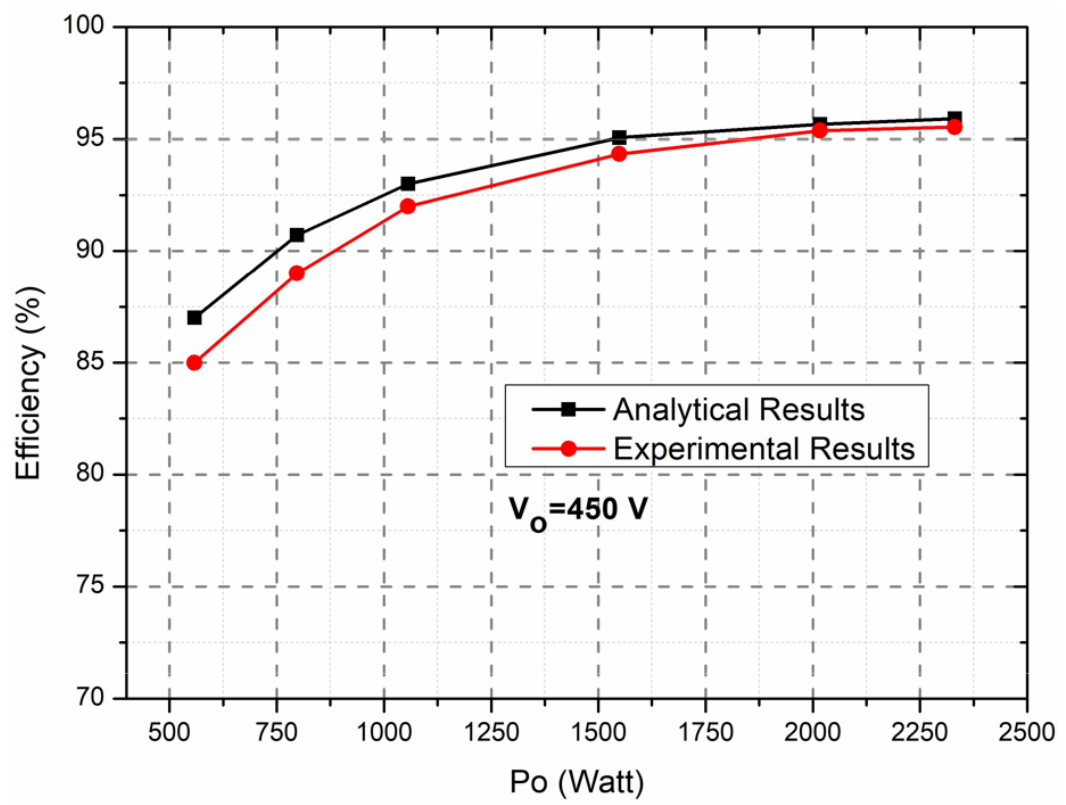

Figure 16. The comparison of analytical and experimental efficiency results for two-stage charger, at different load conditions, with $\mathrm{Vac}_{\mathrm{ac}}=220 \mathrm{~V}, \mathrm{~V}_{\mathrm{o}}=450 \mathrm{~V}$.

The measured CC and CV mode operation characteristic is extracted by the change of electronic load resistance, and obtained characteristics are given in Figure 18. The weight of two-stage charger is measured as $1.938 \mathrm{~kg}$ with $2.5 \mathrm{~kW}$ output power. The total volume of the charger is measured as $1.89 \mathrm{~L}$, and the power density is obtained as $1.3 \mathrm{~kW} / \mathrm{kg}$. The picture of two-stage charger is given in Figure 19.

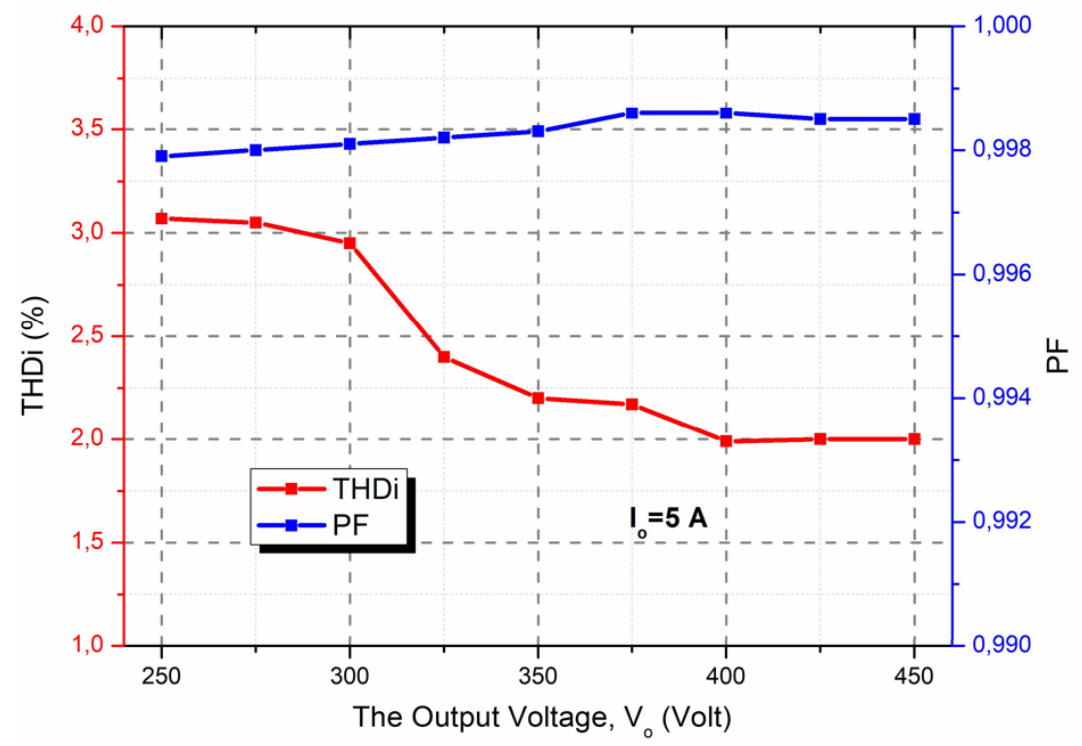

Figure 17. $\mathrm{PF}$ and THDi measurement of two-stage charger based on output voltage variation with $\mathrm{vac}=220 \mathrm{~V},{ }_{\mathrm{o}}=5 \mathrm{~A}$. 


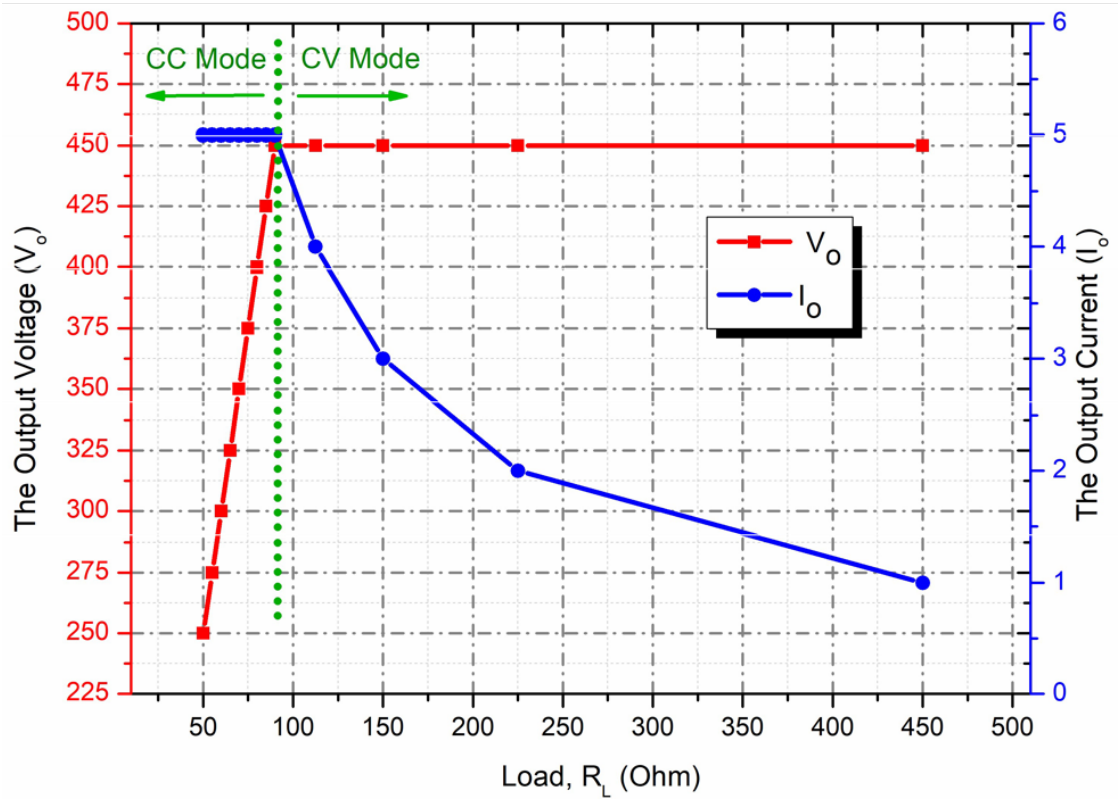

Figure 18. The CC and CV operation characteristic of two-stage charger based on load (RL) values.

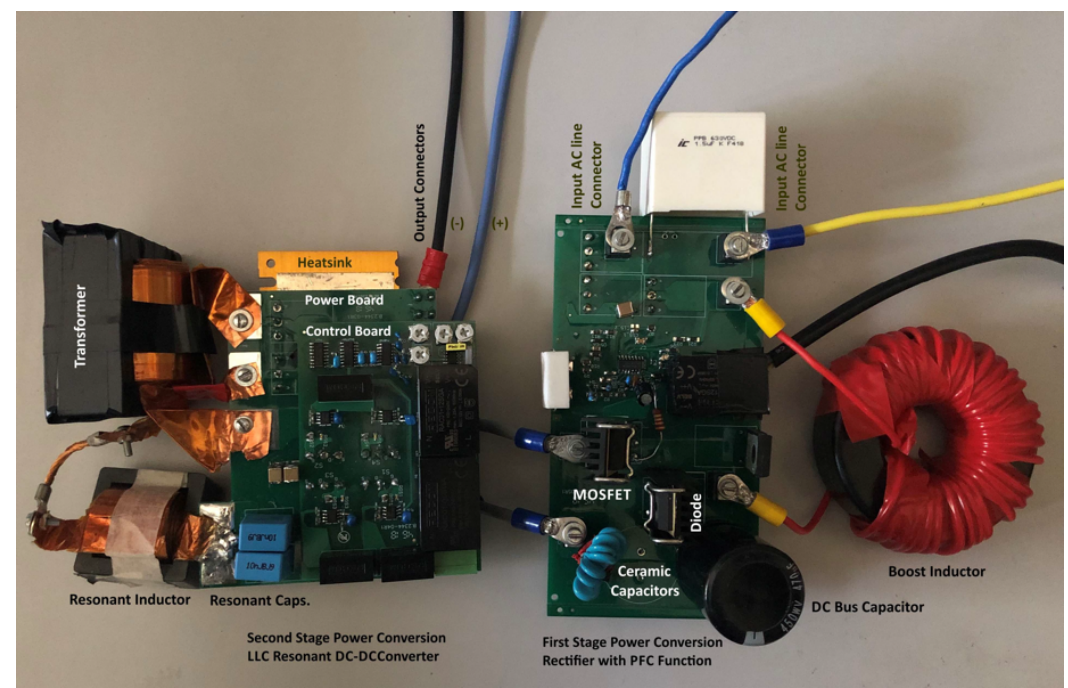

Figure 19. The picture of two-stage charger.

\section{CONCLUSION}

This work presents a design procedure for an on-board EV battery charger using LLC resonant converter. In the proposed design procedure, operation region optimization of LLC resonant converter, high efficiency, wide range output voltage regulation, and load condition which required li-ion battery charge applications, are took into consideration. SiC power semiconductors are adapted to the first stage and the second stage due to their high voltage and high frequency operation capability. The optimal operation region of LLC resonant converter is 
determined below resonance in terms of high efficiency and the output voltage regulation. Finally, a prototype is built to validate the presented design procedure with $2.5 \mathrm{~kW}$ output power and the output voltage range, $250 \mathrm{~V}-450$ $\mathrm{V}$. The peak efficiency of two-stage charger is measured as $95.53 \%$. The total weight and power density of the built prototype are measured as $1.938 \mathrm{~kg}$ and $1.89 \mathrm{~L}$, respectively. Finally, the power density is obtained as 1.3 $\mathrm{kW} / \mathrm{kg}$.

\section{ACKNOWLEDGEMENT}

This work is supported by TUBITAK under grant number 116E125.

\section{REFERENCES}

Badstuebner, U. 2010. Design of an 99\%-efficient, 5kW, phase-shift PWM DC-DC converter for telecom applications. Applied Power Electronics Conference and Exposition (APEC), Palm Springs, USA. https://ieeexplore.ieee.org/document/5433582

Biela, J. 2009. Design of a 5-kW, 1-U, 10-kW/dm3 resonant DC-DC converter for telecom applications. IEEE Trans. on Power Electronics 24:1701-1710.https://ieeexplore.ieee.org/document/5075741

Cetin, S. 2017. High Efficiency Design Approach of A LLC Resonant Converter for On-Board Electrical Vehicle Battery Charge Applications. Pamukkale University Journal of Engineering Science 23:103-110. https://www.journalagent.com/pajes/pdfs/PAJES_23_2_103_111.pdf

Cetin, S. 2018. Optimal Operation Region of LLC Resonant Converter for On-Board EV Battery Charger Applications. IEEE 18th International Conference on Power Electronics and Motion Control, Budapest/Hungary. https://ieeexplore.ieee.org/document/8521857

Chen, M. 2006. Accurate, compact and power-efficient li-ion battery charger circuit. IEEE Trans. Circuits Syst. II, Exp. Briefs 53:1180-1184. https://ieeexplore.ieee.org/document/4012370?section=abstract

Dearborn, S. 2005. Charging li-ion batteries for maximum run times. Power Electronics Technology Magazine 31:40-49. https://www.powerelectronics.com/content/article/21855733/charging-liion-batteriesfor-maximum-run-times

Deng, J. 2014. Design methodology of LLC resonant converters for electric vehicle battery chargers. IEEE Trans. On Vehicular Technology 63:1581-1592. https://ieeexplore.ieee.org/document/6648465

Dow, Y.S. 2011. A study on half bridge LLC resonant converter for battery charger on board. Power Electronics and ECCE Asia (ICPE \& ECCE), Jeju Island. https://ieeexplore.ieee.org/document/5944758

Dow, Y. S. 2015. A study of $6.6 \mathrm{~kW}$ on board charger for electric vehicle. International Electric Vehicle Symposium and Exhibition, Kintex, South Korea. https://pdfs.semanticscholar.org/e243/60704b2d434f67b71fdd7b56cce8a1792258.pdf

Emadi, A. 2006. Power electronics intensive solutions for advanced electric, hybrid electric, and fuel cell vehicular power systems. IEEE Trans. Power Electronics 21:567-577. https://ieeexplore.ieee.org/document/1628996

Emadi, A. 2008. Power electronics and motor drives in electric, hybrid electric, and plug-in hybrid electric vehicles. IEEE Trans. Ind. Appl. 55: 2237-2245. https://ieeexplore.ieee.org/document/4493430 
Fang, Y. 2007. Design of high power density LLC resonant converter with extra wide input range. Applied Power Electronics Conference and Exposition APEC '07, Anaheim, USA.

https://ieeexplore.ieee.org/document/4195837

Fang, X. 2012. Operation mode analysis and peak gain approximation of the LLC resonant converter. IEEE Trans. On Power Electronics 27:1985-1995. https://ieeexplore.ieee.org/document/6021378

Fang, Z. 2015. Optimal design methodology for LLC resonant converter in battery charging applications based on time-weighted average efficiency. IEEE Trans. On Power Electronics 30:5469-5483. https://ieeexplore.ieee.org/document/6981942?denied=

Grenier, M. 2010. Design of on-board charger for plug-in hybrid electric vehicle. Power Electronics, Machine and Drives, Brighton, England. https://ieeexplore.ieee.org/document/5523821

Gu, Y. 2005. Three-level LLC series resonant DC/DC converter. IEEE Trans. On Power Electronics 20:781-789. https://ieeexplore.ieee.org/document/1461459

Haghbin, S. 2010. Integrated chargers for EV's and PHEV's: examples and new solutions. Int. Conf. Electrical Machines, Rome, Italy. https://ieeexplore.ieee.org/document/5608152

Ho, C.N.M. 2013. Acomparative performance study of an interleaved boost converter using commercial Si and SiC diodes for PV applications. IEEE Trans. Power Electronics 28:289-299. https://ieeexplore.ieee.org/document/6198359

Huang, D. 2011. High power density high efficiency DC-DC converter. Energy Conversion Congress and Exposition (ECCE), Phoenix, USA. https://ieeexplore.ieee.org/document/6063942

Kim, D.Y. 2013. Variable delay time method in the phase-shifted full-bridge converter for reduced power consumption under light load conditions. IEEE Trans. Power Electronics 28:5120-5127. https://ieeexplore.ieee.org/document/6403557

Kim, J. W. 2014. Simple switching control technique for improving light load efficiency in a phase-shifted full-bridge converter with a server power system. IEEE Trans. Power Electronics 29:1562-1566. https://ieeexplore.ieee.org/abstract/document/6585822

Lazar, J.F. 2001. Steady-state analysis of the LLC series resonant converter. Applied Power Electronics Conference and Exposition APEC, Anaheim, USA. https://ieeexplore.ieee.org/document/912451

Lu, B. 2006. Optimal design methodology for LLC resonant converter. Applied Power Electronics Conference and Exposition APEC '06, Dallas, USA. https://ieeexplore.ieee.org/document/1620590

Musavi, F. 2013. An LLC resonant DC-DC converter for wide output voltage range battery charging applications. IEEE Trans. Power Electronics 28:5437-5445.

https://ieeexplore.ieee.org/document/6480890?denied=

Mweene, L.H. 1991. A $1 \mathrm{~kW} 500 \mathrm{kHz}$ frontend converter for a distributed power supply system. IEEE Trans. Power Electronics 6:398-407. https://ieeexplore.ieee.org/document/85908

Shafiei, N. 2017. Time Domain Analysis of LLC Resonant Converters in the Boost Mode for Battery Charger Applications. Energy Conversion Congress and Exposition (ECCE), Cincinnati, OH, USA. https://ieeexplore.ieee.org/document/8096721 
Simone, S.D. 2006. Design-oriented steady state analysis of LLC resonant converters based on FHA. International Symposium on Power Electronics, Electrical Drives, Automation and Motion SPEEDAM, Taormina, Italy. https://ieeexplore.ieee.org/document/1649771

Steigerwald, L.R. 1988. A comparison of half bridge resonant converter topologies. IEEE Trans. on Power Electronics 3:174-182. https://ieeexplore.ieee.org/document/4347

Vu, H.N. 2018. A Novel Dual Full-Bridge LLC Resonant Converter for CC and CV Charges of Batteries for Electric Vehicles. IEEE Transactions On Industrial Electronics 65:2212-2225. https://ieeexplore.ieee.org/document/8013847

Wang, H. 2018. PWM LLC Type Resonant Converter Adapted to Wide Output Range in PEV Charging Applications. IEEE Transactions On Power Electronics 33:3791-3801. https://ieeexplore.ieee.org/document/7944637

Whitaker, B. 2014. A high-density, high-efficiency, isolated on-board vehicle battery charger utilizing silicon carbide power devices. IEEE Transactions on Power Electronics 29:2606-2617. https://ieeexplore.iee.org/document/6587577.

Yilmaz, M. 2013. Review of battery charger topologies, charging power levels, and infrastructure for plug-in electric and hybrid vehicles. IEEE Transactions on Power Electronics 28: 2151-2169. https://ieeexplore.ieee.org/document/6280677?tp=\&arnumber=6280677.

$\mathrm{Yu}, \mathrm{R}$. 2012. Computer aided design and optimization of high efficiency LLC series resonant converter. IEEE Trans. Power Electronics 27:3243-3256. https://ieeexplore.ieee.org/document/6104164

Zhao, C. 2009. Optimum design consideration and implementation of a novel synchronous rectified softswitched phase-shift full-bridge converter for low-output-voltage high-output- current applications. IEEE Trans. Power Electronics 24:388-397. https://ieeexplore.ieee.org/document/4752782 